\title{
Sinir stimülatörü içeren bir Kirschner teli ve bahsedilen Kirschner telinin yerleştirme düzeneği
}

\author{
A Kirschner wire containing nerve stimulator and \\ placement apparatus of said Kirschner wire
}

\author{
Selim Safalı \\ Selçuk Üniversitesi Tıp Fakültesi, Ortopedi ve Travmatoloji Ana Bilim Dalı, Konya
}

\begin{abstract}
Kirshner telleri ortopedi ve travmatoloji alanındaki ameliyatlarda sıklıkla kullanılan malzemelerdendir. Pediatrik kırıklar başta olmak üzere açık veya kapalı teknikle uygulanan ameliyatlarda, kanüllü vidalarda, ilizarov gibi eksternal fiksatör tekniklerinde sıklıkla kullanılmaktadır. K-teli (Kirschner teli) çelik malzemeden üretilen, ucu trokar şeklinde, keskin şekilde veya yivli şekilde olabilir. Uygulanırken cerrahi motor yardımı ile kendi ekseni etrafında moment oluşturarak drill yapılmaksızın doğrudan kemiğe gönderilme prensibine dayanır. Gönderim şekli olarak devamlı hareket veya osilasyon hareketi yaparak gönderilebilir. Telin kalınlığı ile ters orantılı olarak fiksasyon (tespit) stabilitesi azalır. Özellikle pediatrik yaş grubunda suprakondiler humerus kırıkları gibi travma hastalarında K-teli ile fiksasyon ilk tercihtir. Çocukların büyümeye devam eden epifiz hattına yakın kırıklarda plak yerleştirmek veya intramedüller tespit yapmak mümkün olmayacağından K-teli altın standart haline gelmiştir. Uygulaması kolay, sonuçları yüz güldürücü ve kozmetik açıdan iyi sonuçlara sahiptir. Bu ameliyatlarda en çok korkulan durum damar sinir yaralanmasıdır. Özellikle dirsek çevresi kırıklarda medialden gönderilen K-teli ulnar sinire yakınlığı nedeniyle risk oluşturmaktadır. $\mathrm{Bu}$ ameliyatlar esnasında kemiğe girmeden önce ve kemikten çıktıktan sonra sinir yaralanmaları görülebilmektedir. Bu komplikasyonların azaltılması amaçlanarak sinir yaralanmasını önleyen Kirshner teli (AYLiZ teli*) geliştirilmiştir. Bu sistem, K-teli ucunda oluşturduğu elektriksel alan sayesinde sinire yaklaştığı zaman, siniri uyararak hareket oluşturmakta ve sinir yaralanmadan önce sinire yaklaşıldığını göstermektedir. Bu sayede daha güvenli bir ameliyat sağlanması planlanmaktadır.
\end{abstract}

Anahtar sözcükler: sinir stimülatorü; K-teli; Kirshner teli; perkutan pinleme; sinir yaralanması
Kirshner wires are frequently used materials in orthopedic surgeries. It is used in open or closed technique surgeries, cannulated screws and external fixator techniques such as Ilizarov, especially in pediatric fractures. K-wire (Kirschner wire) is produced from steel material, the tip can be trocar shaped, sharp or grooved type. While it is applied, it is based on the principle of driving directly to the bone by creating moment around its own axis with the help of a surgical motor. It can be driven as a form of delivery by making continuous movement or movement to the oscillation. Fixation stability decreases inversely with the thickness of the wire. Especially in the pediatric age group, fixation with $k$-wire is the first choice in trauma patients such as supracondilary humerus fractures. K-wire has become the gold standard, as it will not be possible to place plates or make intramedullary fixation in fractures close to the growing epiphyseal line of children. Its easy-to-apply results are pleasant and cosmetically good. The most feared situation in these surgeries is vascular nerve injury. Especially in fractures around the elbow, the k-wire sent from the medial side. It has a risk due to its proximity to the ulnar border. During these operations, nerve injuries can be seen before fixing and after passing the bone. Kirschner wire (* AYLIZ wire), which prevent nerve injury, was developed to reduce these complications. This system stimulates the nerve and creates movement when approaches the nerve by the electrical field. In this way, a safer surgery is planned.

Key words: nerve stimulator; K-wire; Kirschner wire; percutaneous pinning; nerve injury

- İletişim adresi: Dr. Öğr. Üy. Selim Safalı, Selçuk Üniversitesi Tıp Fakültesi, Ortopedi ve Travmatoloji Ana Bilim Dalı, Aleaddin Keykubat Kampüsü, Selçuklu, Konya Tel: 0507 - 7992977 e-posta: selimsafali@gmail.com ORCID iD: 0000-0001-9010-4169

- Geliș tarihi: 24 Kasım 2020 Kabul tarihi: 14 Aralık 2020 


\section{T. C. Türk Patent Enstitüsü'ne Patent Belgesi için Başvuru Bilgileri ${ }^{[1]}$}

Başvuru bilgileri Tablo 1'de gösterilmiştir. ${ }^{[1]}$

Tablo 1. Başvuru bilgileri[1]

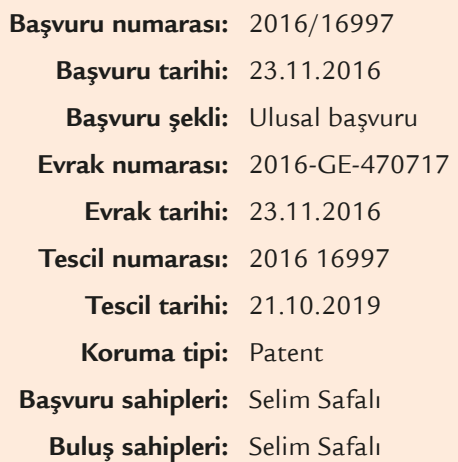

\section{PATENT BELGESI - No: $201616997^{[1]}$}

\section{Teknik Alan ${ }^{[1]}$}

"Buluş, Ilizarov tedavi yönteminde kemik kayıplarını yerine koyma, deforme kemikleri düzeltme ve uzatmada kullanılan ve sinir yaralanmalarını engelleyen Kirschner teli (K-teli) ve bahsedilen Kirschner telinin yerleştirme düzeneği ile ilişkilidir.

Buluş özellikle, sinire yaklaşıldığında, sinirin uyarılması sorucunda kol veya sinirin ulaştığı uzvun hareket etmesini sağlanmasıyla sinire yaklaşıldığını gösteren ve bu sayede sinir yaralanmalarını engelleyen sinir stimülatörü içeren Kirschner teli ve bahsedilen Kirschner telinin yerleștirme düzeneği ile ilgilidir.”

\section{Tekniğin Bilinen Durumu[ ${ }^{[1]}$}

"ilizarov tekniği vücudun pek çok kemiğine dışarıdan sirküler kasnak şeklindeki cisimleri kemiğe teller geçirerek gerdirmek suretiyle yapılan bir ameliyat tekniği olup, kemik kayıplarını yerine koyma ve deforme (eğri) kemikleri düzeltme ve uzatmada kullanılmaktadır. Uygulama doğumsal hastalık, kemik kayıpları veya travmalar sonrası gelişen kol ve bacak eşitsizlikleri olan, çocuk ya da erişkin hastalara uygulanabilmektedir.

Günümüzde ilizarov tekniğiyle ekstremite uzatma, açısal deformasyonlar, açık yaralar ve diğer yöntemlerle tedavi edilemeyen kompleks deformasyonlar da düzeltilmektedir. Bu yöntem ile kemik yapımı uyarılmakta, doku oluşma hızı ve yapı çevresinde kan dolaşımı artırılmaktadır. Bu da kanlanmanın artmasına sebep olmakla ve bu sayede kemik kaynama hızı artırılmış olmaktadır. Kanlanmanın artması, aynı zamanda oluşabilecek veya mevcut olan iltihabın iyileşmesini de hizlandirmaktadır.

Bu yöntemin en önemli problemi Kirschner telinin matkap yardımıyla kemiğe geçirilmesi esnasında oluşan sinir yaralanmalarıdır. Özellikle de dirsek vakalarında kemiğe çok yakın geçen ulnar sinir bu operasyonlarda zedelenebilmektedir. Bunun nedeni de, matkapla sinirin bulunduğu yerin bu teknikte tam olarak tespit edilememesidir."

\section{Buluşun Amacı ${ }^{[1]}$}

"Mevcut buluş, yukarıda bahsedilen gereksinimleri karşılayan, tüm dezavantajları ortadan kaldıran ve ilave bazı avantajlar getiren, sinir stimülatörü içeren bir Kirschner teli ve bahsedilen Kirschner telinin yerleştirme düzeneği ile ilgilidir."

\section{Buluşun Detaylı Açıklaması [1]}

\section{"Şekillerdeki parça referanslarının açıklaması [1]:}

(10) Matkap, (20) Kontrol kumandası, (25) Aktarım elemanı, (30) Kirschner teli, (31) Dış tabaka, (32) Yalıtkan tabaka, (33) iç tabaka, (33.1) Sinir stimilatörü, (34) Iletim bölgesi, (100) Kirschner teli yerleştirme düzeneği, (A) A detayı, (B) B detayı, (C) C detayı.

Şekil 1 ve Şekil 2'de genel perspektif görünümlü verilen Kirschner teli yerleştirme düzeneği (100) en temel haliyle; bahsedilen Kirschner telinin (30) kemik içerisinde hareketini sağlayan bir matkap (10); bahsedilen Kirschner teli (30) ve içerisindeki sinir stimilatörünün (33.1) kontrol edildiği bir kontrol kumandası (20); bahsedilen kontrol kumandası (20) aracılığyla bahsedilen iletim bölgesine (34) uygulanan elektrik akımını ileten aktarım elemanı (25) ve bir dış tabaka (31); elektrik akımı uygulanan bir iç tabaka (33) ve Kirschner telinden (30) oluşmaktadır. Bahsedilen Kirschner teli (30) ise bir dış tabaka (31); elektrik akımı uygulanan bir iç tabaka (33); iç tabaka (33) ve dış tabaka (31) arasına konumlandırılan, iç tabakaya (31) uygulanan elektrik akımının dış tabakaya (31) geçişini engelleyen bir yalıtım tabakası (32); iç tabaka (31) içerisine yerleştirilen ve Kirschner teli (30) sinire yaklaştığında iç tabakaya (31) uygulanan elektrik akımının sinire iletilerek uyarılmasını sağlayan en az bir sinir stimülatörü (33.1) ve bahsedilen iç tabakaya (33) elektrik akımının uygulanmasını sağlayan en az bir iletim bölgesi (34) içermektedir. Şekil 3'te buluş konusu Kirschner telinin (30), Kirschner teli yerleştirme düzeneği (100) üzerinde gösterimi ve Kirschner teline (30) elektrik akımının iletilmesinin sağlayan iletim bölgesinin (34) A detayı gösterilmektedir.

Şekil 4'te ise; Kirschner telinin (30) yandan bir kesit görünümü ve bahsedilen kesit görünümün üzerinde iletim bölgesinin (34) bulunduğu alan Detay B olarak gösterilmektedir. iletim bölgesi (34) direkt olarak iç tabaka (33) ile temas halindedir ve bir aktarım elemanı (25) aracılığıla iç tabakaya (33), aynı zamanda da sinirlerin uyarılmasını sağlamak üzere iç tabaka (33) içerisinde bulunan sinir stimülatörüne (33.1) elektrik akımı sağlamaktadır. Iletim bölgesinin (34) direkt olarak iç tabaka (33) ile temasını sağlamak üzere; Kirschner teli (30) üzerinde dış ortama açık bir kısım bulunmaktadır. Bu iletim bölgesinin (34) çevresi yalıtım 
tabakasılla kaplanmış haldedir, böylece dış tabaka (31) beslenen elektrik akımından etkilenmemektedir.

Buluşun ana amacı, mevcut cerrahilerde kullanılan Kirschner teli içerisine yerleştirilen sinir stimülatörü vasıtasıyla sinire yaklaşıldığı anda bahsedilen stimülatörün uyarı vermesi sonucunda sinirlere telin temas etmesini engellemektedir.

Buluşun amacı K-teli içerisine yerleştirilen sinir stimülatörüne devamlı olarak elektrik akımı vermesiyle sinire yaklaşıldığında sinirin uyarılması sonucunda kol veya sinirin ulaştığı uzvun hareket etmesini sağlamaktadır. Böylelikle sinire yakın olunduğunun fark edilerek yaralanmanın önüne geçilmektedir.

Yukarıda anlatılan amaçların yerine getirilmesi için buluş, kemik kayıplarını yerine koyma, deforme kemikleri düzeltme ve uzatmada kullanılan ve sinir yaralanmalarını engelleyen bir dış tabaka; elektrik akımı uygulanan bir iç tabaka; iç tabaka ve dış tabaka arasına konumlandırılan, iç tabaka uygulanan elektrik akımının dış tabakaya geçişini engelleyen bir yalıtım tabakası; iç tabaka içerisine yerleştirilen ve Kirschner teli sinire yaklaştığında iç tabakaya uygulanan elektirik akımını sinire ileterek uyarılmasını sağlayan en az bir sinir stimülatörü; bahsedilen iç tabakaya elektrik akımının uygulanmasını sağlayan en az bir iletim bölgesi içeren Kirschner teli ve bahsedilen Kirschner telinin kemik içerisine yerleştirilmesini sağlayan bir Kirschner teli yerleştirme düzeneği içermektedir.

Buluşun yapısal ve karakteristik özellikleri ve tüm avantajları aşağıda verilen detaylı açıklama sayesinde daha net olarak anlaşılacaktır ve bu nedenle değerlendirmenin de bu detaylı açıklama göz önüne alınarak yapılması gerekmektedir."

\section{Buluşun Anlaşılmasına Yardımcı Olacak Şekiller ${ }^{[1]}$}

Şekil 1, Kirschner teli yerleştirme düzeneğinin genel perspektif görünümüdür. ${ }^{[1]}$

Şekil 2, Kirschner teli yerleştirme düzeneğinin farklı açıdan perspektif görünümüdür. ${ }^{[1]}$

Şekil 3, Kirschner telinin A detayının görünümüdür. ${ }^{[1]}$

Şekil 4, Kirschner telinin $B$ detayının görünümüdür. ${ }^{[1]}$

\section{Şekil 5, Kirschner telinin C detayının görünümmüdür. ${ }^{[1]}$}

"Şekil 5'te ise Kirschner telinin (30) boydan bir kesiti ve bahsedilen kesitin $C$ detay görünümü verilmektedir. C detayında görüldüğ̈̈ üzere; Kirschner teli (30) dıştan içe doğru; yapıyı bir arada tutan ve diğer katmanları çevreleyen dış katman (31), bahsedilen dış katmanın (31) iç tabakadaki (33) elektrik akımından etkilenmesini engelleyen ve bunu engellemek üzere iç tabakanın (33) etrafinı çevreleyen bir yalıtım tabakası (32) ve en içte bulunan elektrik akımının bir iletim bölgesi (34) aracılığılyla iletildiği iç tabaka (33) içermektedir.

Buluşun tercih edilen bir yapılanmasında; iç tabakada (33) iki adet sinir stimülatörü (33.1) bulunmaktadır. Iç tabaka (33) elektrik akımının uygulandığı katmandır. Bu katmanda konumlandırılan sinir stimülatörleri (33.1) vasıtasıyla sinire yaklaşıldığında, sinirin bulunduğu uzvun hareket etmesi sağlanmakta ve cerrahi işlem yapan kişi uyarılmaktadır. Böylece sinir yaralanmalarına neden olmaksızın, Kirschner teli (30) yerleştirilebilmektedir.

Suprakondiler humerus kırığı, çocuklarda en sık görülen vakalardandır. Kırık yerine oturtularak cilt üzerinden matkap (10) yardımıyla kemik içinden Kirschner teli (30) geçirilmektedir. Kemik üzerinden hasar gören bölgenin stabil edilmesinin ardından kaynama sonrasında bahsi geçen Kirschner telleri ilgili kısımdan çekilmektedir.

Kirschner teli (30) yerleştirme düzeneği (100) çalışma prensibi şu şekildedir:

Kirschner teli (30) operasyon esnasında, matkap (10) tarafindan döndürülmektedir. Matkap (10) üzerinde konumlan ana kontrol kumandasından (20) devamlı olarak elektrik akımı uyarısı verilmektedir. Bu uyarı, aktarım elemanı (25) ve iletim bölgesi (34) aracılığılyla (Kirschner) telinin (30) iç katmanında (33) yer alan sinir stimülatörleri (33.1) üzerinden Kirschner telinin (30) uç noktasına iletilmektedir. Yalıtkan katman (32) vasıtasıyla, gönderilen elektrik sinyallerinin çevreye dağılması engellenmekte ve sadece Kirschner telinin (30) uç noktasından çıkan elektrik sayesinde, telin uç kısmında uyarı oluşturulmaktadır. Böylelikle sinire Kirschner telinin (30) uç kısmı gelmeden sinir uyarılı ve sinir yaralanmasının önüne geçilmiş olunmaktadır.

Söz konusu buluş ile K-teli (30) içerisine yerleştirilen sinir stimülatörüne (33.1) devamlı olarak elektrik akımı verilmesi sayesinde, K-teli (30) sinire yaklaştığında sinirin uyarılması ile operasyonun yapıldığı uzvun hareket ederek operasyonu yapan kişiyi uyarması săglanmıştır dolayısıyla da oluşabilecek sinir yaralanmasının önüne geçilmiştir.”

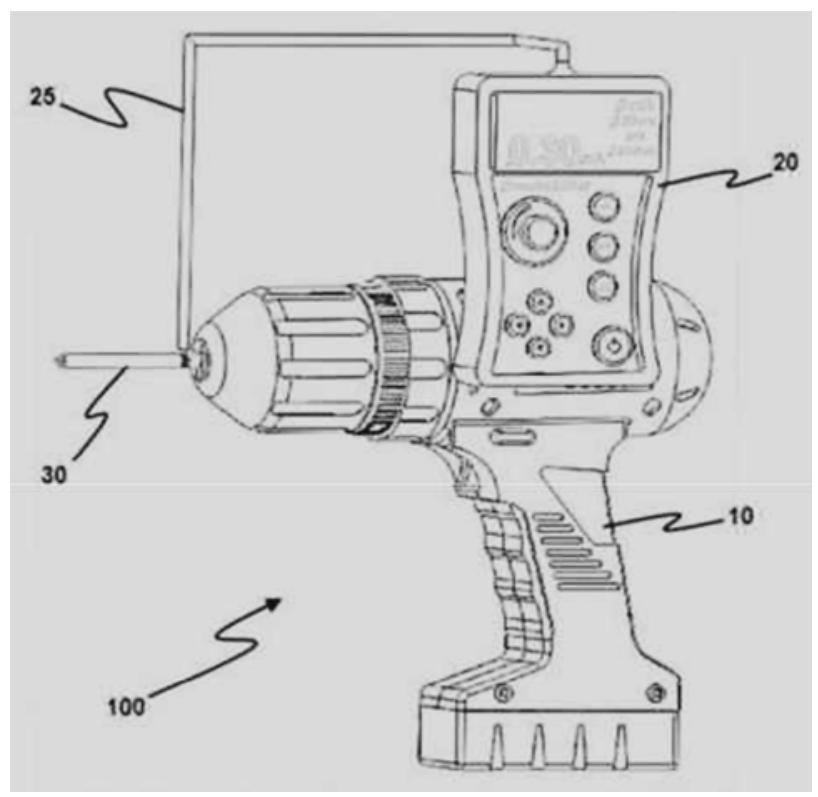

Şekil 1. Kirschner teli yerleştirme düzeneğinin genel perspektif görünümü. 


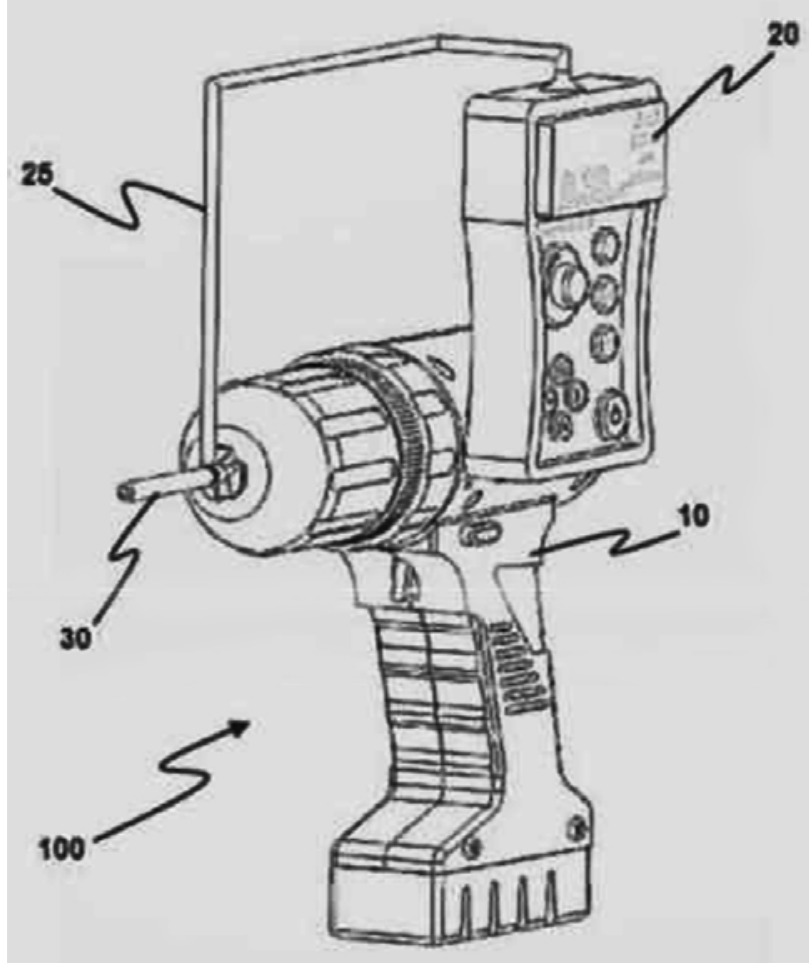

Şekil 2. Kirschner teli yerleştirme düzeneğinin farklı açıdan perspektif görünümü.

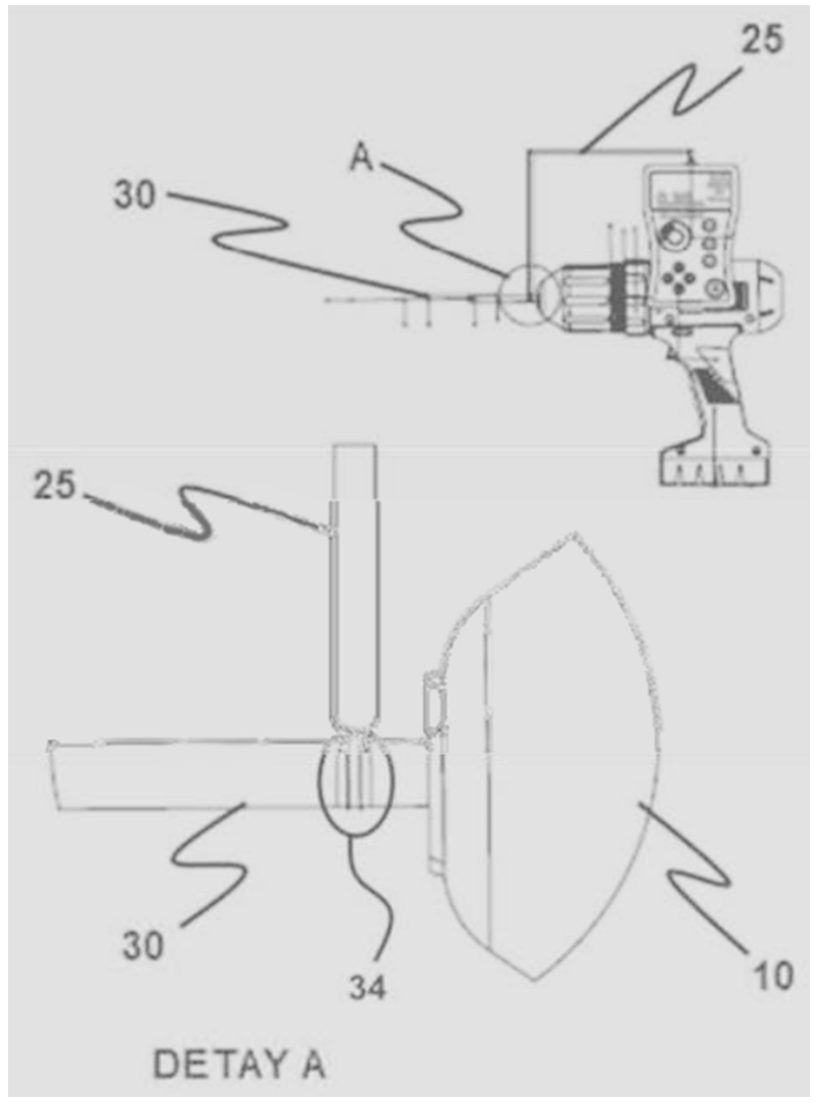

Şekil 3. Kirschner telinin A detayının görünümü.

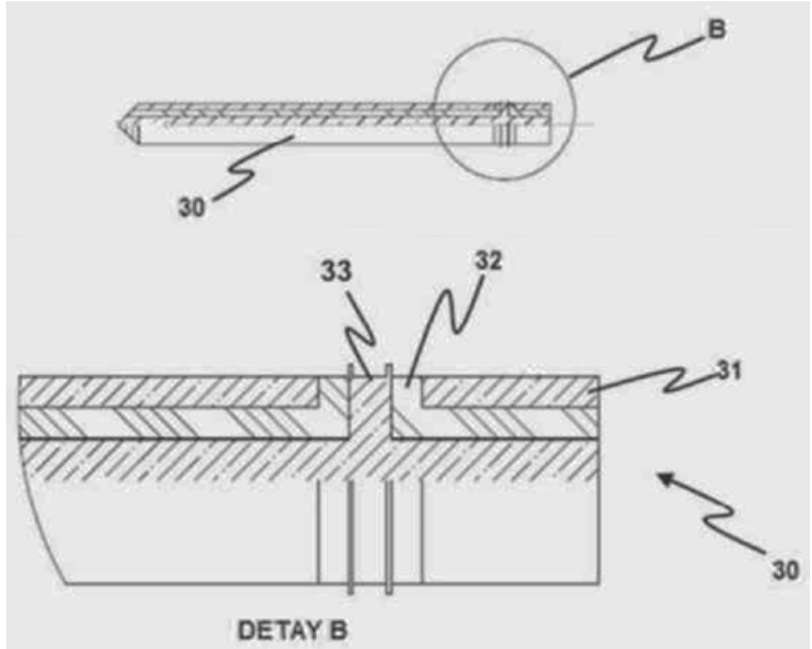

Şekil 4. Kirschner telinin B detayının görünümü.

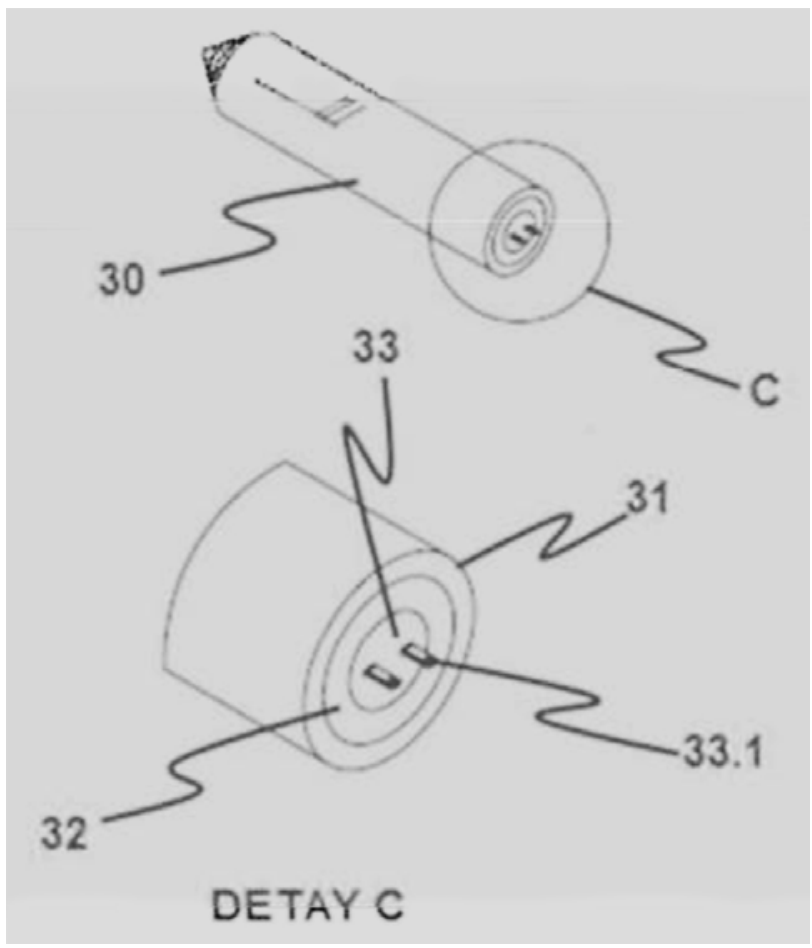

Şekil 5. Kirschner telinin C detayının görünümü.

\section{İstemler ${ }^{[1]}$}

"1. Kemik kayıplarını yerine koyma, deforme kemikleri düzeltme ve uzatmada kullanılan ve sinir yaralanmalarını engelleyen bir Kirschner teli (30) olup, özelliği;

- bir dış tabaka (31),

- elektrik akımı uygulanan bir iç tabaka (33),

- iç tabaka (33) ve dış tabaka (31) arasına konumlandırılan, iç tabakaya (33) uygulanan elektrik akımının dış tabakaya (31) geçişini engelleyen bir yalıtım tabakası (32), 
- iç tabaka (31) içerisine yerleştirilen ve Kirschner teli (30) sinire yaklaştığında iç tabakaya (31) uygulanan elektrik akımını sinire ileterek uyarılmasını sağlayan en az bir sinir stimülatörü (33.1),

- bahsedilen iç tabakaya (33) elektrik akımının uygulanmasını sağlayan en az bir iletim bölgesi (34) içermesidir.

2. Kemik kayıplarını yerine koyma, deforme kemikleri düzeltme ve uzatmada kullanilan Kirschner telinin (30) kemik içerisine yerleştirilmesini sağlayan;

- bahsedilen Kirschner telinin (30) kemik içerisinde hareketini sağlayan bir matkap (10),

- bahsedilen Kirschner teli (30) ve içerisindeki sinir stimülatörünün (33.1) kontrol edildiği bir kontrol kumandası (20), içeren bir Kirschner teli yerleştirme düzeneği (100) olup özelliği;

- bir dış tabaka (31); elektrik elektrik akımı uygulanan bir iç tabaka (33); iç tabaka (33) ve dış tabaka (31) arasına konumlandırılan, iç tabakaya (33) uygulanan elektrik akımının dış tabakaya (31) geçişini engelleyen bir yalıtım tabakası (32); iç tabaka (31) içerisine yerleştirilen ve Kirschner teli (30) sinire yaklaştığında iç tabakaya (31) uygulanan elektrik akımını sinire ileterek uyarılmasını sağlayan en az bir sinir stimülatörü (33.1) ve bahsedilen iç tabakaya (33) elektrik akımının uygulanmasını sağlayan en az bir iletim bölgesi (34) içeren Kirschner teli (30); bahsedilen kontrol kumandası (20) aracılığıla bahsedilen iletim bölgesine (34) uygulanan elektrik akımını ileten aktarım elemanı (25) içermesidir."

\section{YAZARIN KONUYLA ILGILI ÇALIŞMALARI}

Sinir stimülasyonu içeren Kirschner teli ve yerleştirme düzeneği 2019 yılında Türk Patent Enstitüsünden patentlenmiştir. ${ }^{[1]}$

K-telleri 1909 yılında Martin Kirschner tarafından bulunduğundan beri neredeyse hiç değişmeden kullanılmaktadır. Ortopedik cerrahilerde cerrahların her zaman elinin altında bulunması gereken ürünler haline gelmiştir. Traksiyondan ilizarov'a, perkutan pinlemeden kapalı teknik vidalamalara kadar geniş yelpazeye sahip kullanım endikasyonu vardır.

Pediatrik kırıklarda, özellikle suprakondiler kırıklarda K-teli ile fiksasyon en çok kullanılan tedavi yöntemidir. ${ }^{[2]}$ Pediatrik çoğu travmada K-teli ile fiksasyon kullanılmaktadır.

Gönderilen K-teli kemiğe girmeden ulnar sinir hasarı yapabilmekte veya karşı korteksi geçtikten sonra sinir hasarı oluşturabilmektedir. ${ }^{[2]}$ Sadece uç kısmında elektriksel alan olması nedeniyle ilk korteksten önce ve karşı korteksten sonra rahatlıkla uyarı elde edilmektedir. Yine kapalı teknik olarak kullanılan kanüllü vida ve başsız vida sistemlerinde kılavuz teli olarak gönderilebilecek ve iatrojenik (yatrojenik) sinir hasarı önlenecektir. Ayrıca İlizarov tekniğinde, proksimal tibia dan K-teli geçerken peroneal sinir hasarı komplikasyon olarak görülebilmektedir. ${ }^{[3]} \mathrm{Bu}$ sistem yine medialden girilen K-tellerinde karşı korteksten çıktıktan sonra oluşabilecek peroneal yaralanmalar önlenebilecektir. Benzeri şekilde kullanım endikasyonlarını çoğaltmak mümkündür.

Sinir stimülatörleri de tıbbın pek çok alanında halihazırda kullanılmaktadır. Nörologların EMG sistemlerinde ${ }^{[4]}$, vertebra cerrahisinde kullanılan nöromoniterizasyon sisteminde $^{[5]}$, periferik sinir stimülasyonunda ${ }^{[6]}$, tiroid cerrahisinde rekürren laringeal sinir nöromoniterizasyonunda ${ }^{[7,8]}$, vagal sinir stimulasyonunda ${ }^{[9]}$, kulak-burun-boğaz (KBB) alanında fasial sinir moniterizasyonunda $^{[10]}$, rejyonel anestezide ve blok yaparken kullanılmaktadır. ${ }^{[11]}$ Tamamen aynı olmasa da benzer prensiplerde çalışırlar.

Sinire verilen yapay uyarı elektrik iletimi ile sağlanmaktadır. Bu sayede sinirin çevre dokulardaki yakınlığı ayarlanarak sonuç elde edilmektedir. Özellikle cerrahi esnasında komşu sinirlerin doğrudan uyarılması sağlanarak ya da fizyolojik iletim ölçümü esnasında normal uyarı paterninde değişiklik olup olmadığı gözlemlenerek dolaylı yorum yapılmaktadır. Spinal nöromoniterizasyon sisteminde bazal ölçümler esas alınırken, fasial sinir tespitinde doğrudan uyarı sistemi kullanılmaktadır. ${ }^{[10]}$

Tüm bu literatür ve kullanım amaçları çerçevesinde bu sistemin kemik fiksasyonunda kullanılabileceği düşüncesinden yola çıkarak sinir stimülatörlü K-teli (AYLiZ teli) tasarladık.

Bu sistem; sinir stimülatör cihazı, drilleme esnasında sinir iletimi yapabilen cerrahi motor, yalıtılmış K-teli ve bağlantı kablolarından oluşmaktadır (Şekil 6).

K-teli ön ve arka kısmında iletime izin verecek şekilde tasarlanmış iletken kısımlar bulunmaktadır (Şekil 7). Bu sayede K-teli kendi ekseni etrafında dönerken sinir iletimi sağlanmaktadır.

Sistemdeki cerrahi motor kanüllü bir motordur, telin arkasındaki sonradan yerleştirilen düzenek sayesinde $\mathrm{K}$-telinin dönmesine ve sinir iletimine izin vermektedir (Şekil 8).

Dışı yalıtılmış (politetrafloroetilen) bir Kirschner teli ve ucunda trokar şeklinde keskinleştirilmiş yalıtkan kısım bulunmaktadır. Bu uç sayesinde stimülatör cihazından gönderilen akım ile K-teli uç kısmında elektrik alanı oluşturulmaktadır. Bu elektrik alanı 


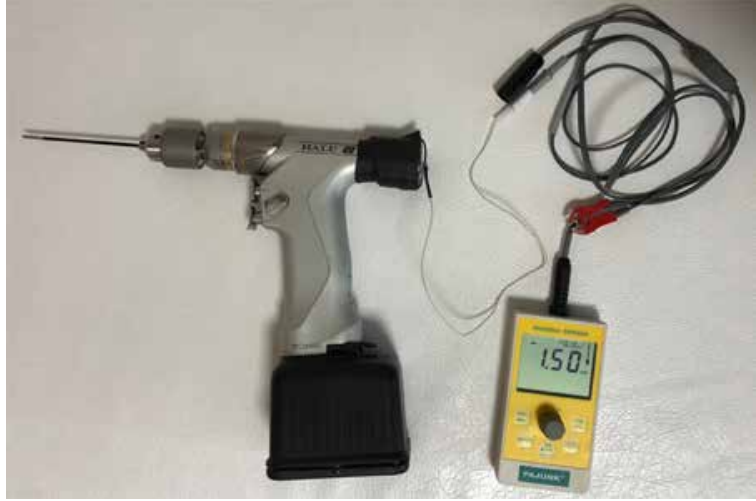

Şekil 6. Prototip görseli; sinir stimülatörü, kablo devresi, sinir iletimine uyarlanmış delici motor, dışı yalıtılmış sinir uyarıcı K-teli birlikte görülüyor.

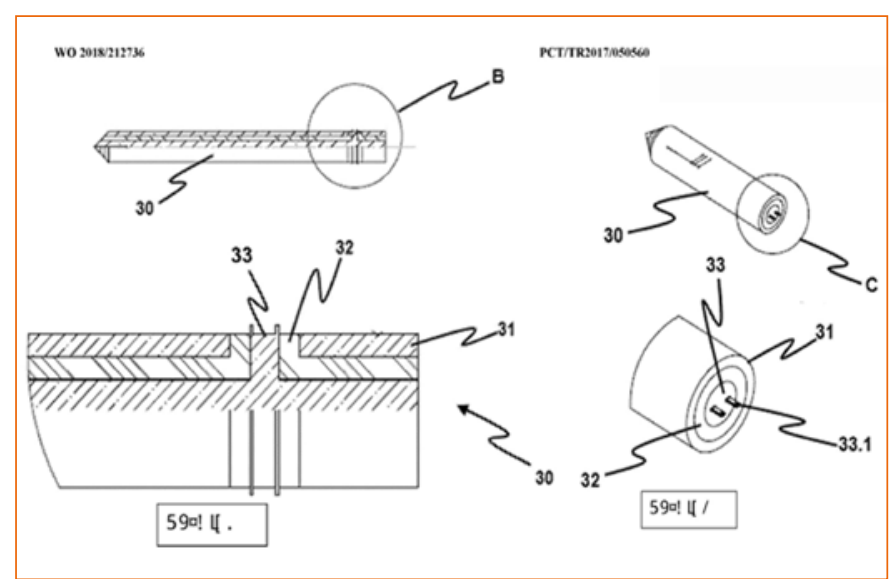

Şekil 7. Sinir stimülatörlü K-teli.

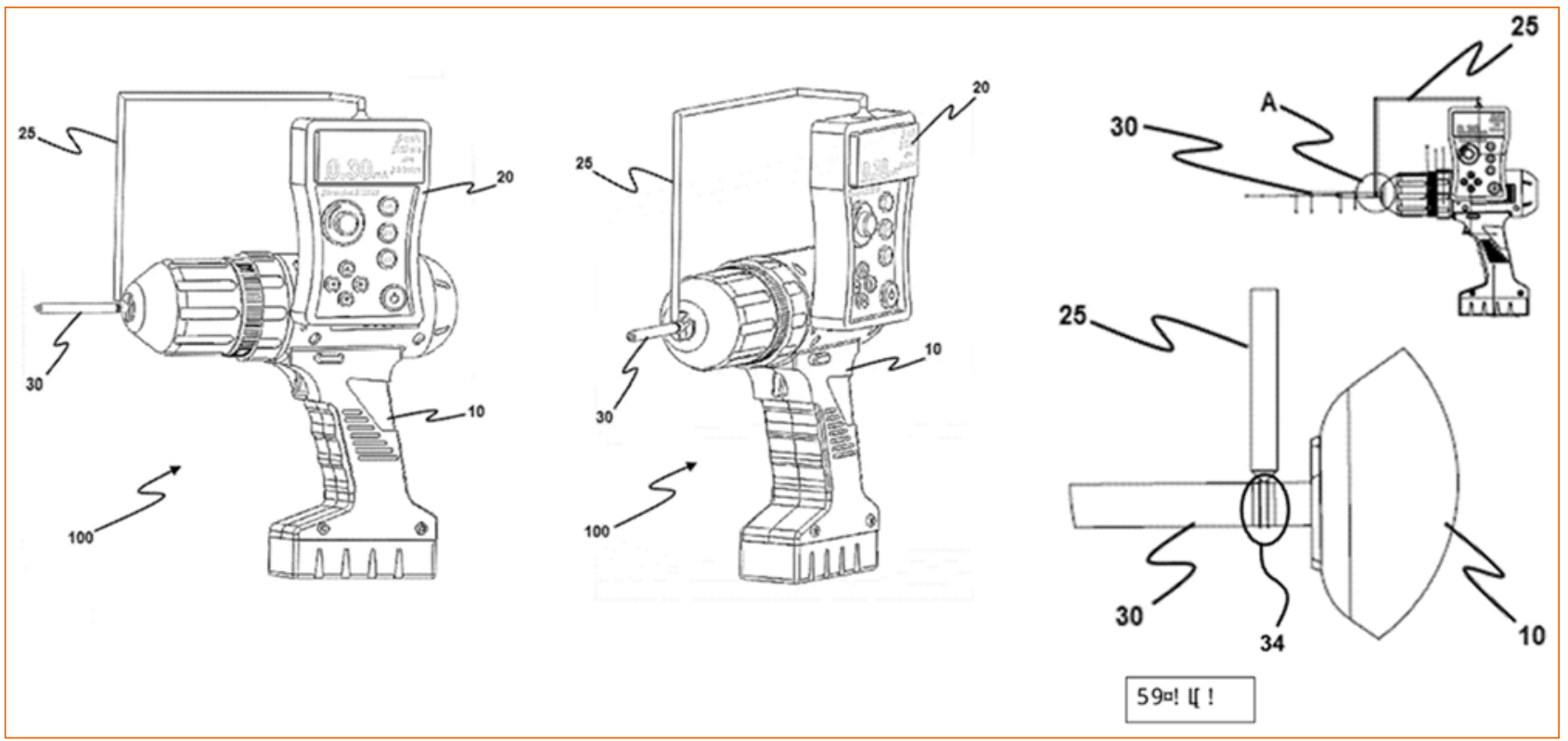

Şekil 8. Şistemin şematik görünümü (patent çizimleridir).

verilen elektrik akımı ile orantılı olarak artmaktadır. $\mathrm{Bu}$ sayede stimülatörden K-teli gönderme esnasında alınmak istenen uyarı, sinir ne kadar uzakta iken elde edilmek isteniyorsa ayarlanabilecektir, yani uyarı sinire $10 \mathrm{~mm}$ kala alınmak istendiği takdirde daha geniş elektrik alanı verilirken, sinire $5 \mathrm{~mm}$ kala uyarı isteniyorsa daha küçük elektrik alanı oluşturulmalıdır. Yine bu sisteme ilave olarak hedef sinirin dermatom ve motor kas gruplarının bulunduğu sahaya elektrik sensörleri yerleştirilmekte ve sinir stimülatöründen çıkan impuls önce motora oradan K-teline ve uyarı verilen sinir trasesi boyunca da sensöre ulaşmaktadır. Sensörden elde edilen impuls motora iletilerek devreyi kesmekte ve drilizasyon işlemini durdurmaktadır.
Bu sayede çok kısa zaman dilimi içinde sinire yaklaşılarak oluşacak hasar önlenmektedir.

Tübitak Marmara Teknokent içerisinde Ar-Ge süreci tamamlanan ve prototipi üretilen ürünün belgelendirme işlemleri devam etmektedir. Çok kısa zaman dilimi içinde de kullanımı mümkün olacaktır.

Not: Buluş sahibi bu ürünün geliştirilmesi esnasında her ortopedi ve travmatoloji ile ilgilenen cerrah gibi ailesine ve çocuklarına ayırdığı zamandan fedakarlık yapmak zorunda kalmıştır. Bu yüzden patentlediği bu buluşa kızının adını vermiştir ( ${ }^{*}$ AYLIZ NEUROPROTECTOR WIRE SYSTEM). 


\section{KAYNAKLAR}

1. Sinir stimülasyonu yapan $K$ teli ve yerleştirme düzeneği , İncelemesiz Patent Belgesi T.C. Türk Patent Ve Marka Kurumu Dairesi Başkanlığı/E.2019-Oe-502745. https://portal.turkpatent. gov.tr/anonim/arastirma/patent/sonuc/dosya?patentAppNo=20 16\%2F16997\&documentsTpye=all

2. Özturkmen Y, Karamehmetoğlu M, Azboy I. Closed reduction and percutaneous lateral pin fixation in the treatment of displaced supracondylar fractures of the humerus in children. Acta Orthop Traumatol Turc 2005;39:396-403. https://aott. org.tr/Content/files/sayilar/450/450-4854.pdf

3. Baruah RK, Harikrishnan SV, Baruah JP. Safe corridor for fibular transfixation wire in relation to common peroneal nerve: A cadaveric analysis. J Clin Orthop Trauma 2019;10:432-8. Crossref

4. Burgess RC. Electrical safety. Handb Clin Neurol 2019;160:67-81. Crossref

5. Laratta JL, Ha A, Shillingford JN, Makhni MC, Lombardi JM, Thuet E, Lehman RA, Lenke LG. Neuromonitoring in Spinal Deformity Surgery: A Multimodality Approach. Global Spine J 2018;8:68-77. Crossref

6. Günter C, Delbeke J, Ortiz-Catalan M. Safety of long-term electrical peripheral nerve stimulation: review of the state of the art. J Neuroeng Rehabil 2019;16:13. Crossref
7. Lawson BR, Kamani D, Shama M, Kyriazidis N, Randolph GW. Safety and reliability of a handheld stimulator for neural monitoring during thyroid surgery. Laryngoscope 2020;130:561-5. Crossref

8. Shin SC, Sung ES, Choi SW, Kim SD, Jung DW, Kim SH, Ro $\mathrm{JH}$, Lee JC, Lee BJ. Feasibility and safety of nerve stimulator attachment to energy-based devices: A porcine model study. Int J Surg 2017;48:155-9. Crossref

9. Makler V, D'Agostino E, Bauer DF. Vagal Nerve Stimulator Lead Revision Using Needle-Tip Cautery: Case Series, Literature Review, and Technical Note. World Neurosurg 2018;117:377-81. Crossref

10. Anso J, Dur C, Apelt M, Venail F, Scheidegger O, Seidel K, Rohrbach H, Forterre F, Dettmer MS, Zlobec I, Weber K, Matulic M, Zoka-Assadi M, Huth M, Caversaccio M, Weber S. Prospective Validation of Facial Nerve Monitoring to Prevent Nerve Damage During Robotic Drilling. Front Surg 2019;6:58. Crossref

11. Ferri CA, Quevedo AAF. High-reliability microcontroller nerve stimulator for assistance in regional anaesthesia procedures. J Med Eng Technol 2017;41:415-24. Crossref 